\title{
PENGEMBANGAN MODEL PERMAINAN UNTUK MENINGKATKAN DAYA TAHAN KARDIORESPIRASI PADA SISWA SEKOLAH DASAR
}

\author{
Widiastuti $^{1}$, Yuliasih ${ }^{2}$, Oki Suryawan ${ }^{2}$ \\ ${ }^{1}$ Universitas Negeri Jakarta, ${ }^{2}$ Universitas Negeri Jakarta
}

Wididila41@gmail.com

\begin{abstract}
Abstrak. Penelitian ini dilakukan untuk memperoleh model permainan yang dapat meningkatkan daya tahan kardiorespirasi pada siswa sekolah dasar. Metode yang digunakan dalam penelitian ini adalah pengembangan Research \& Development (R \& D) dari Borg and Gall, Subyek dalam penelitian ini adalah siswa kelas V SDN Pegangsaan Dua 04 Petang Jakarta Utara yang berjumlah 33 orang. Instrumen yang digunakan untuk pengukuran tes daya tahan kardiorespirasi menggunakan tes lari 600 meter. Hasil penelitian menunjukan pada tes awal nilai tertinggi yaitu 4,48 menit, nilai terendah 7,8 menit dan rata-rata 6,25 menit, pada tes akhir dengan nilai tertinggi 4 menit, nilai terendah 7,2 menit dan rata-rata 5,39 menit.Berdasarkan hasil penelitian tersebut maka dapat disimpulkan 1). model permainan untuk meningkatkan daya tahan kardiorespirasi pada siswa Sekolah Dasar sangat dibutuhkan oleh para guru pendidikan jasmani dan mampu meningkatkan minat belajar secara efektif dan efisien. 2) model permainan yang telah peneliti kembangkan, siswa lebih termotivasi serta aktif dalam mengikuti proses pembelajaran untuk meningkatkan daya tahan kardiorespirasi.
\end{abstract}

Kata Kunci: Pengembangan model, Permainan, Kardiorespirasi.

\section{PENDAHULUAN}

Daya tahan kardiorespirasi sebagai bagian komponen kesegaran jasmani merupakan bagian yang mempunyai pengaruh terhadap kesehatan dan kebugaran jasmani seseorang. Di era globalisasi sekarang ini banyak orang yang menjalani kehidupannya dengan instan seperti penggunaan lift, mobil, dan mesin cuci yang semuanya dikerjakan oleh mesin sebagai hasil dari perkembangan ilmu pengetahuan dan teknologi yang menyebabkan manusia menjadi malas untuk bergerak.

Sejalan dengan usaha pencapaian hasil yang lebih maksimal sebagai suatu proses untuk peningkatan kualitas hidup sudah tentu akan menuntut setiap individu tersebut untuk lebih aktif serta kontinyu dalam berolahraga. Suatu hal penting, namum sering dilupakan sehingga terjadi penurunan kualitas hidup terutama kesehatan yang berhubungan dengan daya tahan kardiorespirasi.

Berbagai upaya untuk meningkatkan daya tahan kardiorespirasi di Indonesia telah merambah dan menjamur diberbagai pusat kebugaran, lembaga pemerintahan sampai ke sekolah. Metode yang digunakan pun bervariasi mulai dari latihan lari di track ataupun di 
treadmill, bersepeda dan senam aerobik. Munculnya fenomena masalah peningkatan daya tahan kardiorespirasi untuk tingkat sekolah berawal dari kurangnya kesegaran jasmani setiap individu dalam menjalankan kegiatan sehari-hari. Padatnya kegiatan di sekolah membuat siswa malas untuk berolahraga. Untuk itu pendidikan jasmani olahraga dan kesehatan perlu dimodifikasi supaya peserta lebih tertarik untuk mengikuti kegiatan tersebut. Tujuannya agar peserta tidak merasa bosan dan merasa nyaman ketika berolahraga.

Proses permainan ini menekankan pada aktifitas fisik seseorang serta memanfaatkan jasmani sebagai alat untuk mencapai tujuan pendidikan yang tujuannya bersifat menyeluruh dan lengkap yang mencakup perkembangan total, berupa: fisik, intelektual, emosional, sosial, moral dan spiritual.

Pendidikan jasmani olahraga dan kesehatan sebagai suatu komponen yang secara keseluruhan telah disadari oleh semua kalangan. Kenyataan di lapangan belum berjalan secara efektif seperti yang diharapkan. Masih konvesionalnya pembelajaran pendidikan jasmani menjadikan pelajaran ini kurang memberikan daya Tarik bagi siswa sebagaimana dikatakan Kirk "summarised traditional physical education pedagogy as "characterized by relatively short units of activity... an overwhelming focus on technique development; a lack ofaccountability for learning and little progression of learning; and the almost exclusive use of a directive teachingstyle".

Peran pendidikan jasmani olahragadankesehatan sangat penting, yakni memberikan kesempatan kepada individu untuk terlibat langsung dalam aneka gerak untuk mendapatkan pengalaman belajar melalui aktivitas jasmani. Hal tersebut merupakan media untuk mendorong perkembangan keterampilan motorik, peningkatan daya tahan kardiorespirasi, kemampuan fisik, pengetahuan dan penalaran, penghayatan nilai-nilai meliputi mental, emosional, spiritual dan sosial serta membiasakan pola hidup sehat yang bermuara untuk merangsang pertumbuhan dan perkembangan yang seimbang.

Pelaksanaan proses pendidikan jasmani olahraga dan kesehatan terkait dengan empat faktor yang tidak dapat dipisahkan satu sama lain, yaitu: tujuan, materi, metoda, dan evaluasi. Salah satu prinsip penting dalam olahraga adalah partisipasi peserta secara penuh dan merata.

Penelitian ini, fokus utamanya adalah bagaimana cara mengembangkan model permainan untuk meningkatkan daya tahan kardiorespirasi. Selanjutnya diperlukan upaya untuk perbaikan kekurangan-kekurangan dalam proses pendidikan jasmani olahraga dan kesehatan serta mencari jalan keluar dan berupaya agar pendidikan jasmani olahraga dan kesehatan menjadi kegiatan yang menyenangkan, membahagiakan, meningkatkan kebugaran jasmani, serta dapat memperkaya pengalaman gerak atau motorik peserta sebagai dasar-dasar gerak cabang olahraga lainnya. Sehingga hasil penelitian ini dapat dijadikan salah satu bahan ajar dalam meningkatkan proses pendidikan jasmani olahraga dan kesehatan yang berkelanjutan.

Pendidikan Jasmani. Pendidikan jasmani merupakan bagian dari pendidikan di sekolah dari tingkat dasar sampai perguruan tinggi. Pelaksanaan pendidikan jasmani sering dinomorduakan karena dianggap tidak penting, padahal pendidikan jasmani merupakan penyeimbang beban berat di 
sekolah yang dapat menyebabkan kebosanan yang permanen pada siswa. Sejatinya dalam pendidikan jasmani terkandung nilai-nilai yang bermakna, seperti yang dikatakan oleh Hopper, Grey dan Trish Maude yang mengatakan "physical education is about at each key stage, lists the key aspects, which are important for all children, that should be taught and states the expectations for children's knowledge, understanding and skills by the end of key stage". Dari penjelasan tersebut dapat diketahui bahwa pendidikan jasmani pada setiap tahap memiliki unsur yang penting bagi semua anak, yang harus diajarkan. Dalam pemebelajaran pendidikan jasmani siswa diharapkan dapat mengembangkan keterampilan fisik, mengkaitkan Antara pengetahuan yang mereka peroleh dengan praktik di lapangan, membuat penilaian sederhana tentang apa yang mereka lakukan, membangun kreativitas dan antusiasme untuk melakukan aktivitas fisik, menggunakan lingkungan indoor dan outdoor sebagai sarana belajar. Anak belajar untuk bekerja sama.

Permainan. Definisi "permainan" yang banyak dianut oleh para pakar adalah yang dilontarkan oleh Huizinga, yang terkenal lewat buku Homo Lundes. Huizinga berupaya untuk menggutamakan ciri atau sifat bermain dalam kegiatan manusia dengan mendenifisikan play, bermain sebagai: 1. avoluntary, activity, axisting, outside, "ordinary" life. 2. totally upsorbing 3. Unproductive 4. accuning within a circumscribed time and space 5. ordered by rules 6 . characterrized by group relationships which surround themselves by secrecy and disguise.

Menurut Claparade dalam Satya, bermain bukan hanya memberikan pengaruh positif terhadap pertumbuhan organ tubuh anak yang disebabkan aktif bergerak tetapi bermain juga berfungsi sebagai proses sublimasi artinya suatu pelarian dari perasaan tertekan yang berlebihan menuju hal-hal posiif, melalui sublimasi anak akan menuju kearah yang lebih mulia, lebih indah dan lebih kreatif.

Pada dasarnya karakteristik anak usia sekolah dasar mengedepankan unsur bermain dalam setiap prosesnya, hal itu di gunakan untuk membangkitkan rasa berfikir kreatif. Bermain juga dapat diartikan sebagai aktifitas apapun yang dipilih secara bebas, intrinsik, termotivasi dan diarahkan secara pribadi.

Untuk itu pendekatan yang diberikan dalam meningkatkan daya tahan kardiorespirasi menggunakan metode berbentuk permainan agar pembelajaran menjadi lebih menarik, memicu pemikiran yang inovatif dan memberikan keragaman metode pembelajaran sehingga dapat membuat siswa termotivasi dan menimbulkan kesenangan.

Permainan yang bersifat edukatif dapat berfungsi sebagai ilmu pengetahuan kepada anak melalui proses pemberian pembelajaran bermain sambil belajar, merangsang pengembangan daya pikir, daya cipta, dan bahasa, agar dapat menumbuhkan sikap, mental, serta akhlak yang baik, menciptakan lingkungan bermain yang menarik, memberikan rasa aman, dan menyenangkan, menciptakan kualitas pembelajaran anak-anak.

Rangkaian dalam sebuah permainan harus mengedepankan unsur kesenangan, adanya motivasi intrinsik, proses yang berorientasi, bebas memilih serta terlibat langsung secara aktif. Namun hal ini harus dilakukan dengan menyesuaikannya pada karakteristik anak usia sekolah dasar.

Daya Tahan Kardiorespirasi. Kesegaran jasmani adalah kemampuan 
seseorang untuk melakukan tugasnya sehari-hari dengan mudah tanpa merasa lelah yang berlebihan dan masih mempunyai cadangan tenaga untuk menikmati waktu senggangnya untuk keperluan yang mendadak. Begitupun Kesegaran jasmani pada anak usia sekolah dasar sangat penting untuk pahami "Physical fitness in childhood is a marker of health as it reflects the functional status of most the body functions involved in the performance of daily physical activity and/or physical exercise. Measurement and monitoring of these indicators of health beginning from early age is of highest importance". kebugaran fisik di masa kanak-kanak merupakan penanda kesehatan karena mencerminkan status fungsional sebagian besarfungsi tubuh yang terlibat dalam kinerja aktivitas fisik sehari-hari.

Dalam hal ini daya tahan kardiorespirasi menyangkut masalah otot jantung. Semakin kuat otot jantung maka akan besar pula memompakan darah ke seluruh otot. Dalam kesegaran jasmani terdapat komponen-komponen kesegaran jasmani yang harus dimiliki oleh seseorang agar dapat melakukan aktivitasnya sehari-hari, yaitu: daya tahan kardiovaskuler (Cardivasculer Endurance), daya tahan otot (Muscle Endurance), kekuatan otot (Muscle Strength), kelentukan (Fleksibility) dan komposisi tubuh (Body Compotition).

Adapun faktor - faktor yang mempengaruhi daya tahan kardiorespirasi yaitu:

1. Genetik (Keturunan). Daya tahan kardiovaskuler dipengaruhi oleh faktor genetik yakni sifat-sifat spesifik yang ada dalam tubuh seseorang sejak lahir. Penelitian dari Kanada telah meneliti perbedaan kebugaran aerobik diantara saudara kandung (dizygotic) dan kembar identik (monozygotic) dan mendapati bahwa perbedaannya lebih besar pada saudara kandung dari pada kembar identik.Baru-baru ini, Manila dan Bouchard telah memperkirakan bahwa herediter bertanggung jawab atas 25-40\% dari perbedaan nilai $\mathrm{VO}_{2} \mathrm{Max}$ dan Sundet, Magnus Tambs berpendapat bahwa lebih dari setengah perbedaan kekuatan maksimal aerobik dikarenakan oleh perbedaan genotype, dan faktor lingkungan (nutrisi) sebagai penyebab lainnya. Ini mendukung pendapat bahwa cara untuk menjadi atlet berdaya tahan tinggi adalah dengan memilih orang tua dengan teliti. Kita mewarisi banyak faktor yang memberikan konstribusi pada kebugaran aerobik, termasuk kapasitas maksimal sistem respiratori dan kardiovaskuler, jantung yang lebih besar, sel darah merah dan hemoglobin yang lebih banyak. Pengaruh genetik pada kekuatan otot dan daya tahan otot pada umumnya berhubungan dengan komposisi serabut otot yang terdiri dari serat merah dan serat putih. Seseorang yang memiliki lebih banyak lebih tepat untuk melakukan kegitan bersifat aerobic, sedangkan yang lebih banyak memiliki serat otot rangka putih, lebih mampu melakukan kegiatan yang bersifat anaerobik. Berdasarkan penelitian yang telah ada mengemukakan bahwa volume oksigen maksimal 93,4\% ditentukan oleh faktor genetik dan dapat diubah hanya dengan latihan. Demikian pula pengaruh keturunan terhadap komposisi tubuh, sering dihubungkan dengan tipe tubuh. Seseorang yang mempunyai tipe endomorf 
(bentuk tubuh bulat dan pendek) cenderung memiliki jaringan lemak yang lebih banyak bila dibandingkan dengan tipe otot ektomorf (bentuk tubuh kurus dan tinggi).

2. Jenis Kelamin, Sampai dengan usia pubertas tidak terdapat perbedaan antara laki-laki dan perempuan, setelah usia tersebut nilai pada wanita lebih rendah 15 $25 \%$ dari laki-laki. Perbedaan tersebut disebabkan oleh adanya perbedaan maximal muscular power yang berhubungan dengan luas permukaan tubuh, komposisi tubuh, kekuatan otot, jumlah haemoglobin, kapasitas paru-paru dan sebagainya.

3. Usia, Mulai anak-anak sampai sekitar usia 20 tahun daya tahan jantung meningkat dan mencapai maksimal pada usia 20-30 tahun dan kemudian berbanding terbalik dengan usia sehingga pada orang yang berusia 70 tahun diperoleh daya tahan $50 \%$ dari daya tahan yang dimiliki ketika usia 17 tahun. Hal ini disebabkan oleh penurunan faal organ transport dan penggunaan oksigen yang terjadi akibat bertambahnya usia. Akan tetapi hal ini dapat diperlambat dengan melakukan latihan aerobik.

4. Komposisi Tubuh, Walaupun $\mathrm{VO}_{2} \mathrm{max}$ dinyatakan dalam beberapa milliliter oksigen per $\mathrm{kg}$ berat badan per menit, perbedaan komposisi tubuh seseorangg menyebabkan konsumsi oksigen yang berbeda. Brian J Sharkey mengemukakan bahwa " $\mathrm{VO}_{2}$ max seseorang dihitung per unit berat badan, jadi jika lemak meningkat maka $\mathrm{VO}_{2}$ max seseorang akan menurun".Perbedaan komposisi tubuh seseorang menyebabkan konsumsi oksigen yang berbeda.

5. Latihan, Efek langsung dari olahraga atau latihan fisik yang paling dirasakan adalah meningkatnya derajat jantung dan frekuensi pernafasan sebagai reaksi adaptasi dari tubuhnya akan terjadi beberapa perubahan penting pada sistem jantung dan peredaran darah, seperti peningkatan tegangan (tones) otot polos dari arteri, peningkatan daya difusi oksigen $\left(\mathrm{O}_{2}\right)$ dan karbondioksida $\left(\mathrm{CO}_{2}\right)$ dalam kapiler paru-paru dan jaringan lainnya, peningkatan volume kuncupan jantung dan meningkatnya denyut jantung maksimum.

\section{METODE}

Penelitian pengembangan ini adalah menghasilkan sebuah produk berupa model-model permainan untuk meningkatkan daya tahan kardiorespirasi sehingga dapat membantu proses belajar siswa mengenai permainan secara lebih efektif, efisien menarik dan variatif agar tidak membosankan.

Penelitian ini akan dilaksanakan di SD Negeri Pegangsaan Dua 04 PetangJakarta Utara. Waktu penelitian ini dilaksanakansebanyak 6 kali pertemuan. Penelitian dan pengembangan ini menggunakan pendekatan kualitatif serta menggunakan model pengembangan Research \& Development $(R \& D)$ dengan Flow Chart.

Pada penelitian pengembangan ini teknik analisis data yang digunakan adalah teknik analisis deskriptif kuantitatif dengan prosentase. Teknik ini digunakan untuk menganalisa data kuantitatif yang diperoleh dari hasil penyebaran angket evaluasi dari pakar 
olahraga permainan dan pakar pendidikan jasmani mengenai hasil produk yang dikembangkan. Rumus untuk mengolah tanggapan atau evaluasi dari pakar olahraga permainan dan pakar pendidikan jasmani. Untuk menentukan kesimpulan yang telah tercapai maka ditetapkan kriteria sebagaimana pada tabel berikut:

Tabel 1. Analisis Persentase Hasil Evaluasi Oleh Subyek Uji coba

\begin{tabular}{ccc}
\hline Persentase & Keterangan & Makna \\
\hline $80 \%-100 \%$ & Valid & Digunakan \\
$60 \%-79 \%$ & Cukup & Dalid \\
$50 \%-59 \%$ & $\begin{array}{c}\text { Kurang } \\
\text { Valid }\end{array}$ & Diganti \\
$<50 \%$ & Tidak Valid & Diganti \\
\hline
\end{tabular}

\section{HASIL DAN PEMBAHASAN}

Berdasarkan hasil uji coba kelompok besar (field try-out) yang dilakukan terhadap model yang berjumlah 29model yang tertuang pada tabel di atas diperoleh skor hasil sebesar 296 dari skor maksimal 348 dengan rata-rata persentase hasil penggunaan model sebesar $85 \%$ sehingga pada penggunaan keseluruhan model pada pengembangan ini dapat dikategorikan valid dan cocok untuk digunakan dalam pengembangan model permainan untuk meningkatkan daya tahan kardiorespirasi. Menurut pendapat dari para ahli pada pengembangan model permainan untuk meningkatkan daya tahan kardiorespirasi yang telah diujicobakan dalam uji coba kelompok besar (field try-out),ternyata penggunaan model yang telah dikembangkan tidak ada yang perlu direvisi karena tidak semua aspek memenuhi standar.

Produk yang dikembangkan ini bertujuan untuk membantu meningkatkan tercapainya tujuan pendidikan jasmani khususnya meningkatkan daya tahan kardiorespirasi pada siswa sekolah dasar. Model ini dibuat berdasarkan tingkat kebutuhan anak dalam aktivitas gerak, yang secara psikologis anak-anak kelas V usia 11-12 tahun ini lebih senang dengan aktivitas bermain, maka dalam model ini penerapannya dilakukan dengan prinsip permainan.

Hasil ujicoba tahap kedua penggunaan model ini ternyata menghasilkan target yang diharapkan, artinya model ini sudah efektif untuk memenuhi kebutuhan peningkatan daya tahan kardiorespirasi pada siswa sekolah dasar. Subyek yang diambil dalam penelitian adalah sekolah yang belum memiliki sarana prasarana olahraga yang memadai. Hal ini memberikan satu pandangan bahwa ketika model ini diterapkan di sekolah yang memiliki sarana dan prasarana olahraga yang lengkap, maka pelaksanaannya akan lebih baik dan sempurna lagi.

Produk ini setelah dikaji mengenai beberapa kelemahan yang perlu pembenahan sesuai diatas maka dapat disampaikan beberapa keunggulan produk ini antara lain:

1. Siswa lebih aktif dalam mengikuti proses belajar sambil melalui permainan.

2. Memperkaya gerak siswa akan tetapi tetap pada konsep multilateral, terutama pada beberapa permainan seperti menciptakan gerakan

3. Walaupun memerlukan sarana yang lebih banyak dan memadai dari pada pembelajaran konvensional,akan tetapi konsep "bermain sambil belajar" mampu diterapkan. Hal ini tentu sangat sesuai dengan karakteristik siswa usia 10-12 tahun. 
4. Siswa terlihat gembira dan antusias dalam mengikuti permainan yang diberikan.

5. Permainan dilakukan dengan memulainya dari permainan yang tidak menggunakan alat ke permainan yang menggunakan alat.

Penelitian pengembangan model permainan untuk meningkatkan daya tahan kardiorespirasi ini memiliki item tes untuk mengukur daya tahan kardiorespirasinya yaitu dengan pengukuran tes lari 600 meter pada siswa sekolah dasar dan dinilai dengan waktu yang ditempuh.

Adapun deskripsi data pada penelitian ini meliputi nilai tertinggi, nilai terendah dan rata-rata serta distribusi frekuensi dan histogram tes awal dan tes akhir lari 600 meter siswa sekolah dasar yang aka tergambar jelas dengan tabel 4.7 dibawah ini:

\section{Tabel 2. Deskripsi Data Pengukuran Tes Awal dan Akhir Lari 600 Meter pada Siswa Sekolah Dasar}

\begin{tabular}{lccc}
\hline No & Variabel & $\begin{array}{c}\text { Tes Awal } \\
\text { (Menit) }\end{array}$ & $\begin{array}{c}\text { Tes Akhir } \\
\text { (Menit) }\end{array}$ \\
\hline 1 & Nilai Tertinggi & 4,48 & 4 \\
2 & Nilai Terendah & 7,8 & 7,2 \\
3 & Rata-rata & 6,25 & 5,39 \\
\hline
\end{tabular}

Berdasarkan tabel 2 . dijelaskan bahwa pengukuran tes awal lari 600 meter pada siswa sekolah dasar menunjukkan rentangan nilai tertinggi 4,48; nilai terendah 7,8 dan rata-rata 6,25 . Sedangkan hasil pengukuran tes akhir lari 600 meter pada siswa sekolah dasar menunjukkan nilai tertinggi 4; nilai terendah 7,2 dan rata-rata 5,39. Hal tersebut dapat dilihat lebih jelas pada tabel distribusi frekuensi dan histogram dibawah ini:

Tabel 3. Distribusi Frekuensi

Pengukuran Tes Awal Lari 600

Meter pada Siswa Sekolah Dasar

\begin{tabular}{ccccc}
\hline No & $\begin{array}{c}\text { Kelas } \\
\text { Interval }\end{array}$ & $\begin{array}{c}\text { Nilai } \\
\text { Tengah }\end{array}$ & $\begin{array}{c}\text { Frekuensi } \\
\text { Absolut }\end{array}$ & $\begin{array}{c}\text { Frekuensi } \\
\text { Relatif (\%) }\end{array}$ \\
\hline 1 & $7,25-8,00$ & 7,63 & 4 & 12,1 \\
2 & $6,25-7,00$ & 6,63 & 11 & 33,3 \\
3 & $5,25-6,00$ & 5,63 & 16 & 48,5 \\
4 & $4,25-5,00$ & 4,63 & 2 & 6,1 \\
5 & $3,25-4,00$ & 3,63 & 0 & 0 \\
Jumlah & & & 33 & 100 \\
\hline
\end{tabular}

Tabel 4. Distribusi Frekuensi

Pengukuran Tes Akhir Lari 600 Meter pada Siswa Sekolah Dasar

\begin{tabular}{ccccc}
\hline No & Kelas Interval & $\begin{array}{c}\text { Nilai } \\
\text { Tengah }\end{array}$ & $\begin{array}{c}\text { Frekuensi } \\
\text { Absolut }\end{array}$ & $\begin{array}{c}\text { Frekuensi } \\
\text { Relatif (\%) }\end{array}$ \\
\hline 1 & $7,50-8,00$ & 7,75 & 1 & 3,0 \\
2 & $6,50-7,00$ & 6,75 & 8 & 24,3 \\
3 & $5,50-6,00$ & 5,75 & 12 & 36,4 \\
4 & $4,50-5,00$ & 4,75 & 11 & 33,3 \\
5 & $3,50-4,00$ & 3,75 & 1 & 3,0 \\
& Jumlah & & 33 & 100 \\
\hline
\end{tabular}

Berdasarkan data pada tabel 4 menunjukkan bahwa terjadi penurunan waktu pada saat pengukuran tes lari 600 meter pada siswa sekolah dasar, hal ini menunjukkan bahwa adanya peningkatan daya tahan karidorespirasi dari tes awal ke tes akhir yang dilakukan. Untuk memperjelas hal tersebut, maka peneliti sajikan grafik penurunan waktu pengukuran tes lari 600 meter sebagai berikut: 


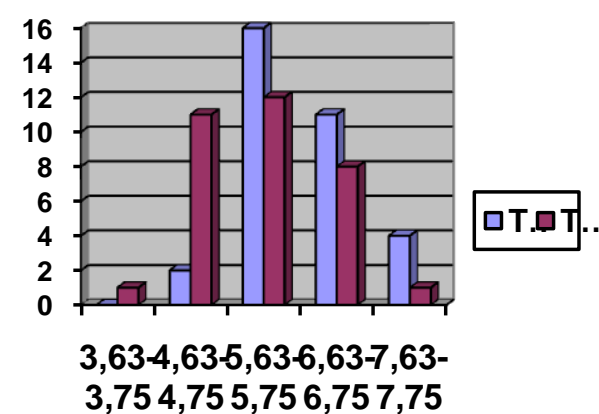

Gambar 1. Grafik Tes Awal dan Tes Akhir Lari 600 Meter pada Siswa Sekolah Dasar

Grafik diatas menggambarkan adanya perubahan waktu antara pengukuran tes awal dan pengukuran tes akhir lari 600 meter pada siswa sekolah dasar. Hal ini menunjukkan bahwa permainan yang dikembangkan oleh peneliti untuk meningkatkan daya tahan kardiorespirasi pada siswa sekolah dasar berhasil.

\section{KESIMPULAN}

Berdasarkan data yang diperoleh, dari hasil ujicoba kelompok kecil dan ujicoba lapangan serta pembahasan hasil penelitian, dapat disimpulkan bahwa:

1. Model permainan untuk meningkatkan daya tahan kardiorespirasi pada siswa sekolah dasar sangat dibutuhkan oleh para guru pendidikan jasmani untuk dapat meningkatkan semangat belajar siswa.

2. Dengan model permainan yang telah peneliti kembangkan, siswa lebih termotivasi serta aktif dalam mengikuti proses pembelajaran.

3. Siswa mampu mengembangkan gerakan melalui permainan yang diberikan.

4. Siswa dapat mengikuti proses belajar dengan baik karena adanya peningkatan daya tahan kardiorespirasi.
5. Variasi dari model permainan yang peneliti kembangkan mampu membuat siswa tertarik untuk mengikuti pelajaran pendidikan jasmani, olahraga dan kesehatan.

\section{DAFTAR PUSTAKA}

Bev Hopper, L. G. Teaching Physical Education in The Primary School. USA: Routledge Falmer, 2000.

Borg. W. R \& Gall, M. D. Educational Research An Introduction. New York: Longman, 1983.

Boyle, Susan. Teaching Toolkit : An Introduction to Games Based Learning. UCD Teaching And Learning/ Resources, 2011.

Brian J Sharkey. Kebugaran dan Kesehatan. Jakarta: Raja Grafindo Persada, 2003.

Brigita Miežienè, L.G. functional physical fitness in 7-10-year-old school children in lithuania. Pilot study (pp. 40 - 46) baltic journal of sport \& health sciences, 2017.

Departemen Kesehatan Republik Indonesia Direktorat Jenderal Pembinaan Kesehatan Masyarakat Direktorat Bina Upaya Kesehatan Puskesmas. Pedoman Pengukuran Kesegaran Jasmani. Jakarta, 1994.

Goldstein, Jeffrey. Play in Children's Development Health and Well Being. Boulevard de Waterloo: Toy Industries of Europe, 2012.

Ismail, Andang. Education Games. Yogyakarta : Pilar Media, 2006.

Kirk, D. Future prospects for teaching games for understanding. In L. Griffin \& J. Butler (Eds), Teaching games for understanding: Theory, research 
and practice (pp. 213 - 227).

Champaign Illinois: Human

Kinetics, 2005.

Sukirman D. Permainan Tradisional Jawa.Kepel Press Purwanggan, 2005.

White, Rachel. E. The Power of Play: A Research Summary on Play and Learning. St. Paul: Minnesota Children's Museum Smart Play, 2012.

Wira Indra Satya. Membangun Kebugaran Jasmani dan Kecerdasan Melalui Bermain (Jakarta: Depdiknas Dirjen Dikti Direktorat Ketenagaan), 2006. 